\title{
VELOCITY FILTERING OF SEISMIC CORE PHASES
}

\author{
By W. J. Hannon* and R. L. Kovach*
}

\begin{abstract}
A.BSTRACT
Recent studies have proposed complexities in the velocity-depth function for the region surrounding the inner core which require additional branches in the travel time curve for PKP in the epicentral range of $125^{\circ}$ to $160^{\circ}$. The proposed PKP arrivals can be separated on the basis of their apparent velocities, which range from $24 \mathrm{~km} / \mathrm{sec}$ to $100 \mathrm{~km} / \mathrm{sec}$. Using the Tonto Forest array in Arizona coupled with adjoining LRSM stations in the western United States, an effective linear array of $400 \mathrm{~km}$ in size is attained. Data from several events in the distance range from $130^{\circ}$ to $160^{\circ}$ recorded on this array have been velocity filtered and show some evidence of two precursors to PKP in the distance range from $135^{\circ}$ to $143^{\circ}$ and at least one intermediate branch between $P K P_{1}$ and $P K P_{2}$ at distances greater than $143^{\circ}$. The results appear to support the velocity solution for the core proposed by Adams and Randall, although more data are required before a conclusive discrimination can be made between competing velocity models.
\end{abstract}

\section{INTRODUCTION}

The presence of a small, possibly solid, inner core with a radius of about $1250 \mathrm{~km}$ was proposed by Lehmann in 1936 to explain observations of PKP phases in the shadow zone. This hypothesis was adopted by both Gutenberg and Richter (1938) and Jeffreys (1939 a, b). The velocity models proposed by these investigators were quite similar in the interior of the inner core, but differed markedly in the transition zone at the boundary of the inner core. At present, the nature of this boundary is still open to speculation and the existence of shear waves in the inner core has not been established.

As the quantity and quality of seismological data have increased, various investigators (Gutenberg, 1957, 1958 a, b, 1959; Hai, 1961, 1963; Bolt, 1962, 1964; Adams and Randall, 1963, 1964) have observed events which appear to be core phases that are not explained by the original velocity models of Jeffreys and Gutenberg and Richter. In particular, arrivals preceding the main PKP phase have been observed at distances less than $140^{\circ}$ and triplication of $P K P$ has been noted beyond $143^{\circ}$. Because of these observations, various modifications to the early velocity models have been proposed (Figure 1).

Since the observed core arrivals are separated by less than 15 seconds over most of their observable range, it is difficult to use travel time data alone to examine the validity of the proposed models. Furthermore, variations in the relative amplitudes of the different phases and uncertainty as to which phase is the first arrival

*W. J. H. now at Department of Earth Seiences, Washington University, St. Louis. R. L. K. now at Department of Geophysies, Stanford University, Stanford, California. 
in certain distance ranges, complicate the problem. When the uncertainties due to multiple phases from shallow focus earthquakes, and possible errors in epicenter locations, depth of foci, and origin time are also considered, it is necessary that criteria other than travel times be used for phase identification.

One such criterion is the slope of the travel time curve or the apparent surface velocity. The apparent velocities for the various PKP arrivals are considerably

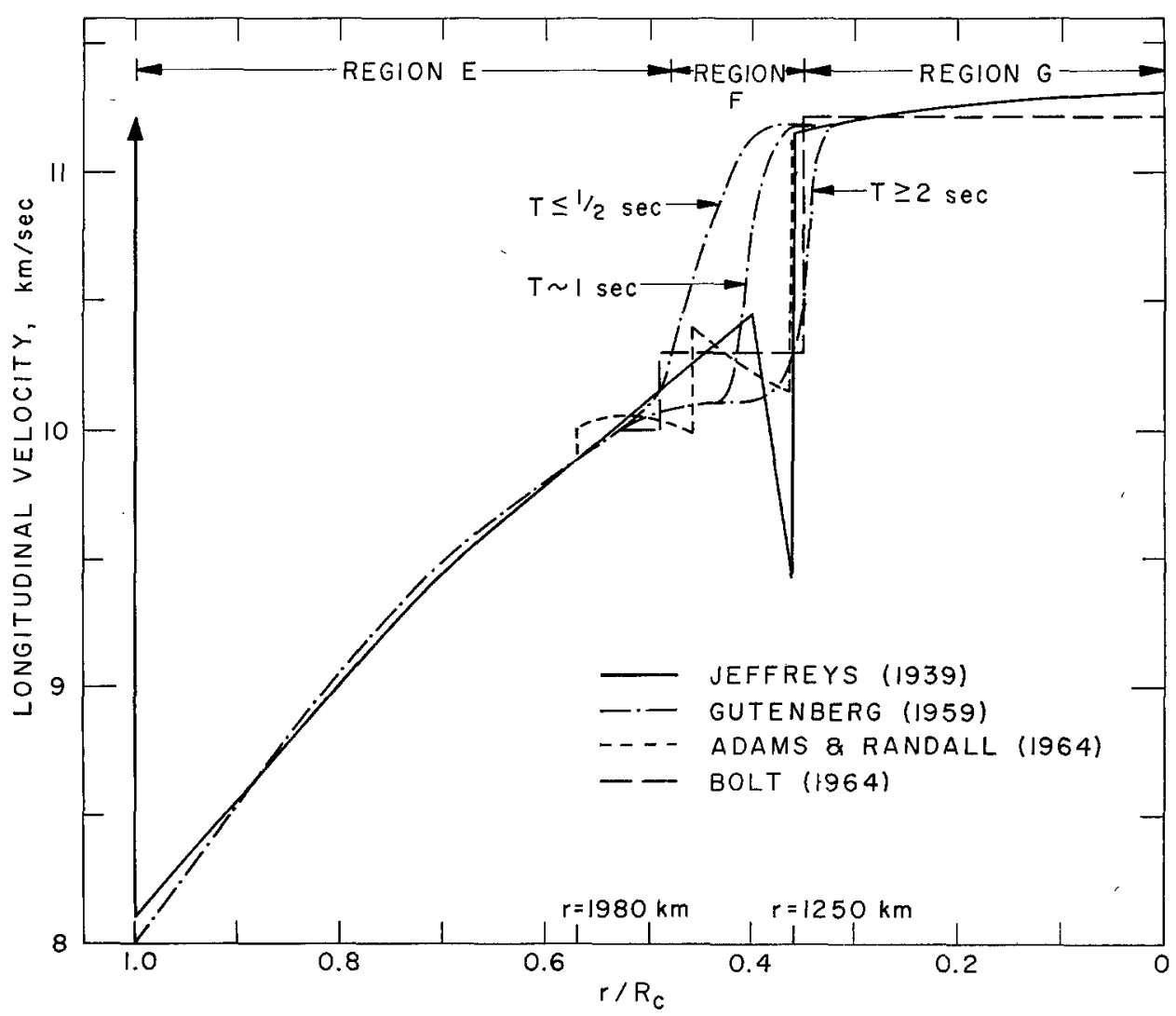

FIg. 1. Proposed longitudinal velocity distributions in the earth's core. The velocity distribution proposed by Hai (1963) is similar to that of Gutenberg for $T>2$ sec with the addition of two small regions with negative gradient at $r / R_{c}=0.36$ and 0.54 .

different, ranging from $24 \mathrm{~km} / \mathrm{sec}$ to over $100 \mathrm{~km} /$ sec. A large array of seismographs can be used to employ velocity filtering as a technique of phase identification. We have used the Tonto Forest (TFO) crossed array in Arizona combined with surrounding portable Long Range Seismic Measurement (LRSM) stations to form an array of about $400 \mathrm{~km}$ in linear dimension. The use of velocity filtering as a method of phase identification is not new, but this is the first time that it has been applied to the analysis of phases emerging from the transition zone at the boundary of the inner core. 


\section{Theoretical Travel Times and Apparent Velocities}

The most important differences in the velocity models occur at the transition zone between the inner and outer core (Figure 1). The familiar Jeffreys (1939 b) solution has a transition region with a large negative velocity into the inner core. Gutenberg's (1958 b) model has a frequency-dependent velocity distribution which gives the increase in velocity without the region of negative velocity gradient. The modification of Jeffreys' model proposed by Adams and Randall (1964) has three discontinuous velocity increases joined by regions with small negative velocity

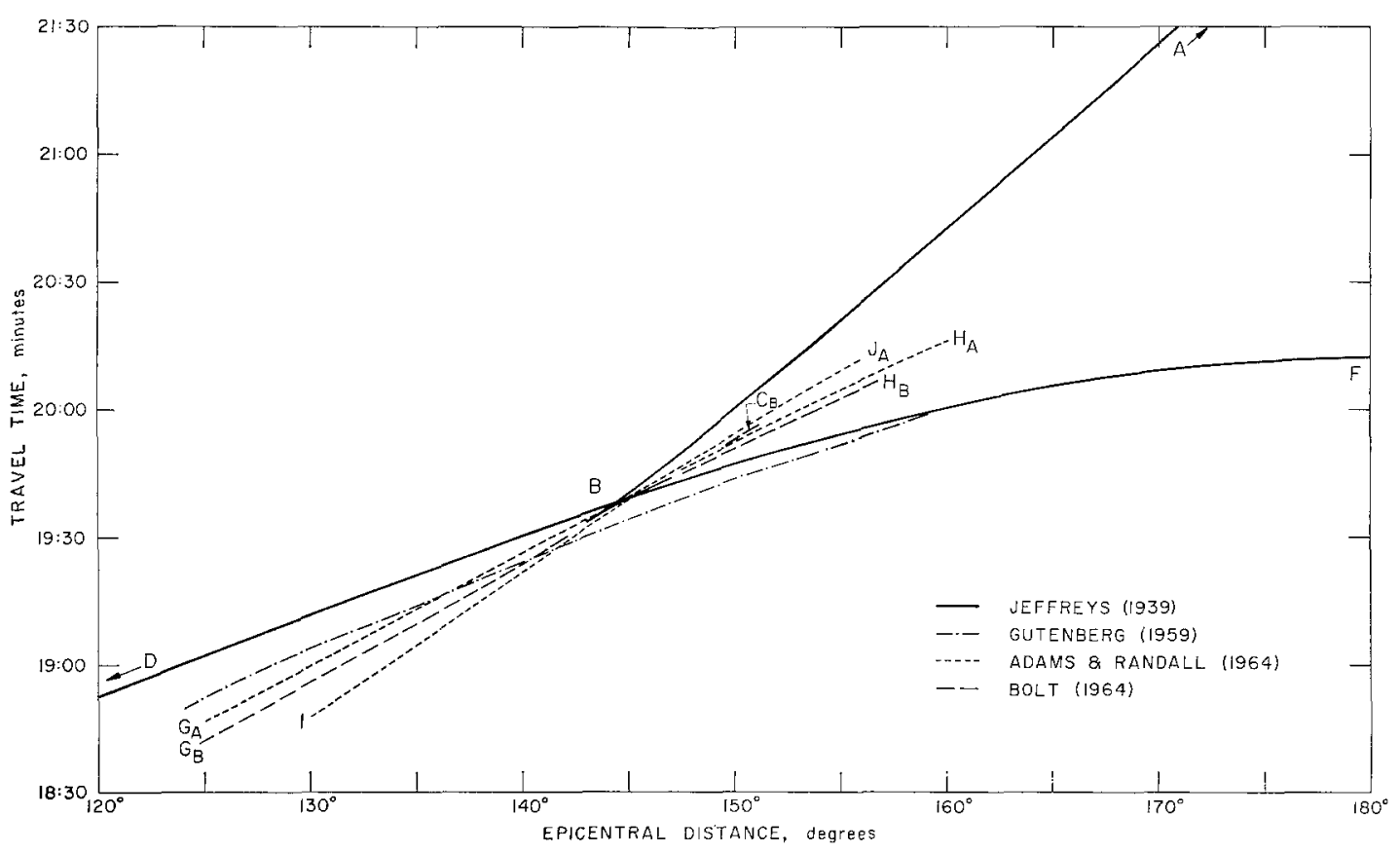

FIG. 2. Travel time curves for PKP. Hai's model has a branch combining features of $I J$ from $137^{\circ}$ to $143^{\circ}$ and $G H$ from $143^{\circ}$ to $157^{\circ}$. It also has a short period precursor similar to Gutenberg in the range $128^{\circ}$ to $137^{\circ}$.

gradients; whereas, the model proposed by Bolt (1962) has two discontinuous velocity increases joined by a region of constant velocity. Hai's (1963) model is not shown in Figure 1 but it is quite similar to the $T \geqq 2$ second solution of Gutenberg except for a small dip in the velocity at a radius of about $1920 \mathrm{~km}$.

The distinctive features of the various travel time curves predicted by these models are compared to the familiar Jeffreys model in Figure 2. We shall follow the notation proposed by Adams and Randall (1964) for the various PKP arrivals. The two main branches $P_{A B}^{\prime}$ and $P_{D F}^{\prime}$ are quite similar for all the models. Jeffreys' solution has a cusp at $143^{\circ}$ followed by a short branch $P_{B O}^{\prime}$ from $143^{\circ}$ to $147^{\circ}$. Gutenberg's model also has a caustic at $143^{\circ}$, but the branch $P_{B C}^{\prime}$ extends to distances greater than $160^{\circ}$. The most distinctive feature of the travel time curve for Guten- 
berg's model, however, is the presence of a short period (about 1 second) precursor which arrives 3 to 10 seconds earlier than $P_{D F}^{\prime}$ at distances less than $143^{\circ}$.

The modification proposed by Bolt (1964) predicts a precursor $P_{G H}^{\prime}$ before $P_{D F}^{\prime}$ at distances less than $143^{\circ}$. This precursor becomes an intermediate phase between $P_{D F}^{\prime}$ and $P_{A B}^{\prime}$ at distances from $146^{\circ}$ to $156^{\circ}$. The cusp at $B$ is preserved and $P_{B C}^{\prime}$ extends to approximately $152^{\circ}$. On the other hand, Adams and Randall's (1964) solution has two precursors $\left(P_{I J}^{\prime}\right.$ and $P_{G H}^{\prime}$ ) to $P_{D F}^{\prime}$ at distances less than $143^{\circ}$.

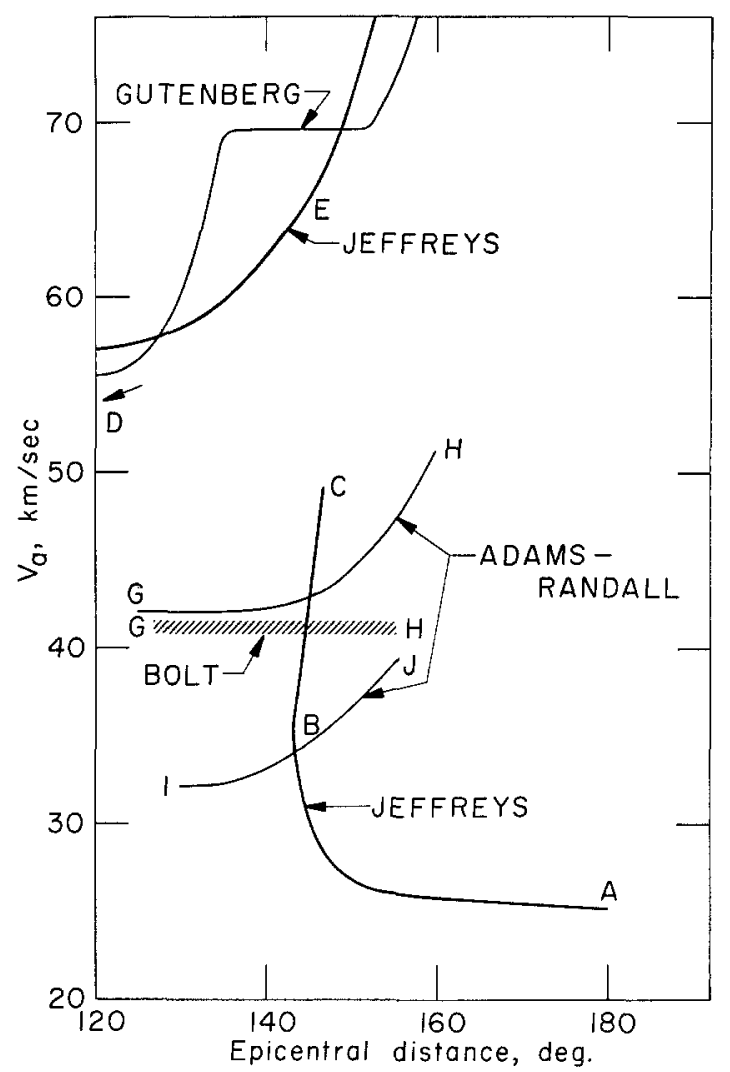

FIG. 3. Apparent surface velocities for the proposed core phases.

The first of these, $P_{I J}^{\prime}$, precedes the main $P_{D F}^{\prime}$ arrival by more than 17 seconds at distances less than $134^{\circ}$. The later precursor $P_{G H}^{\prime}$ is very similar to that predicted by Bolt's model. In addition to having two precursors, the Adams and Randall travel time curve is unique, in that it has no cusp at $143^{\circ}$ and $P_{r J}^{\prime}$ replaces $P_{B C}^{\prime}$ at distances greater than $143^{\circ}$. The excellent observational data of Hai (1963) indicate a precursor to $P_{D F}^{\prime}$ by about 12 seconds at $137^{\circ}$. His data also support the extension of $P_{B C}^{\prime}$ to $157^{\circ}$.

Figure 3 shows the apparent surface velocities for the proposed phases. The velocities for the phases are considerably different except for the proposed $G H$ and $I J$ branches. Thus, with even a few stations in an array, it is relatively easy to identify $P_{A B}^{\prime}$ and $P_{D F}^{\prime}$. It is then a simple matter to locate other phases with 
respect to these arrivals. If a more dense array is available, it may be possible to identify $P_{I J}^{\prime}$ and $P_{G H}^{\prime}$ from their apparent surface velocities.

\section{Observational Data}

The Tonto Forest linear crossed array (TFO), when combined with adjacent Long Range Seismic Measurement (LRSM) stations forms an effective large array $400 \mathrm{~km}$ in dimension. Figure 4 and Table 1 show the locations and coordinates of

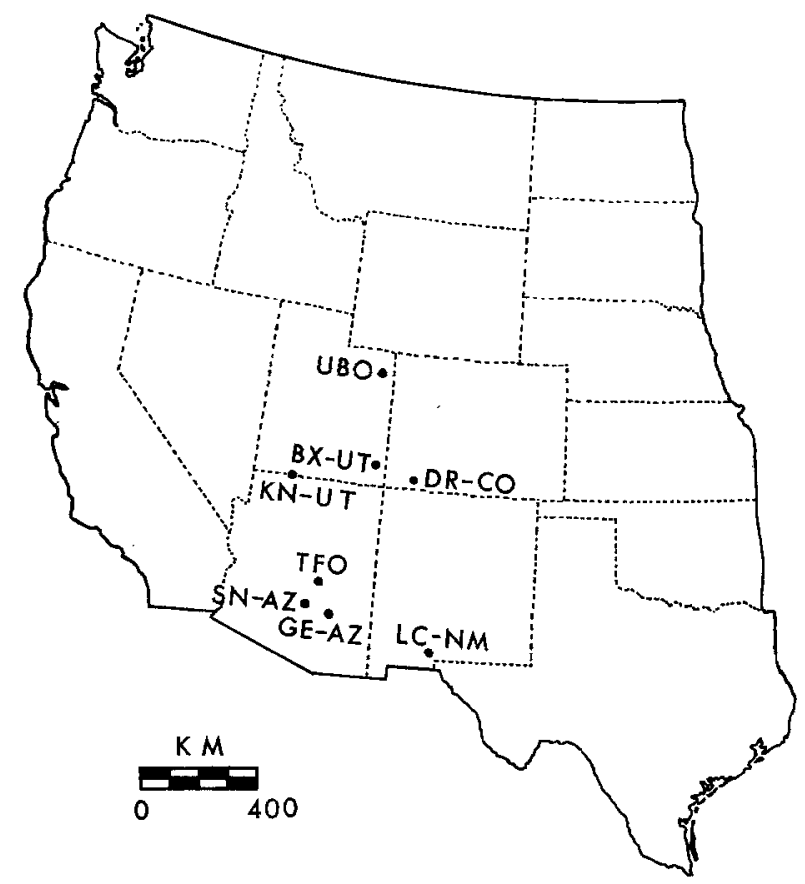

Fig. 4. The locations of the Tonto Forest array and surrounding LRSM stations in the western United States.

the stations used. TFO operates Johnson-Matheson short period seismometers at magnifications of about 500,000 at a period of 1 second. The surrounding LRSM stations operate short period Benioff seismometers at gains from $\frac{1}{3}$ to $\frac{1}{4}$ those at TFO. Both horizontal and vertical seismometers are installed at many of these sites. However, only vertical instruments were used in this study since the angles of incidence at the free surface are less than $20^{\circ}$ for the phases analyzed.

From the events recorded at TFO, we selected 15 earthquakes (Table 2) which had particularly well defined core phases. For six of these earthquakes the corresponding LRSM records together with the records from other array stations were examined. The recording stations used corresponding to the events listed in Table 2 are given in Table 3. Sample seismograms showing typical core phases recorded at TFO are shown in Figure 5. The top two traces correspond to events 5 and 13 from Sumatra $\left(\Delta=132.7^{\circ}\right)$ and Java $\left(\Delta=135.1^{\circ}\right)$, respectively. Although the epicentral distances of the two events differ by only $3^{\circ}$ and the focal depths are about 
the same, the two records differ considerably. The Java earthquake has a precursor, possibly corresponding to the $P_{I J}^{\prime}$ branch of Adams and Randall, but this event is not observable on seismograms of the Sumatra earthquake recorded at distances of about $132^{\circ}$. This difference cannot be explained on the basis of magnitude since

TABLE 1

Coordinates of Recording Stations

\begin{tabular}{l|l|c|c}
\hline Station Code & Station Name & N. Latitude & W. Longitude \\
\hline BMO & Blue Mountain & $44^{\circ} 50^{\prime} 56^{\prime \prime}$ & $117^{\circ} 18^{\prime} 20^{\prime \prime}$ \\
BX-OT & Blanding & $37^{\circ} 33^{\prime} 48^{\prime \prime}$ & $109^{\circ} 26^{\prime} 05^{\prime \prime}$ \\
DR-CO & Durango & $37^{\circ} 27^{\prime} 53^{\prime \prime}$ & $107^{\circ} 47^{\prime} 00^{\prime \prime}$ \\
GE-AZ & Globe & $33^{\circ} 46^{\prime} 32^{\prime \prime}$ & $110^{\circ} 31^{\prime} 41^{\prime \prime}$ \\
JR-AZ & Jerome & $34^{\circ} 49^{\prime} 32^{\prime \prime}$ & $111^{\circ} 59^{\prime} 25^{\prime \prime}$ \\
KM-CL & Kramer & $34^{\circ} 52^{\prime} 52^{\prime \prime}$ & $117^{\circ} 15^{\prime} 24^{\prime \prime}$ \\
KN-UT & Kanab & $37^{\circ} 01^{\prime} 22^{\prime \prime}$ & $112^{\circ} 49^{\prime} 39^{\prime \prime}$ \\
LC-NM & Las Cruces & $32^{\circ} 24^{\prime} 08^{\prime \prime}$ & $106^{\circ} 35^{\prime} 58^{\prime \prime}$ \\
LG-AZ & Long Valley & $34^{\circ} 24^{\prime} 28^{\prime \prime}$ & $111^{\circ} 32^{\prime} 45^{\prime \prime}$ \\
SN-AZ & Sunflower & $33^{\circ} 51^{\prime} 49^{\prime \prime}$ & $111^{\circ} 41^{\prime} 34^{\prime \prime}$ \\
TFO & $34^{\circ} 17^{\prime} 12^{\prime \prime}$ & $111^{\circ} 16^{\prime} 03^{\prime \prime}$ \\
UBO & Tonto Forest & $40^{\circ} 19^{\prime} 18^{\prime \prime}$ & $109^{\circ} 34^{\prime} 07^{\prime \prime}$ \\
WMO & Uinta Basin & $34^{\circ} 43^{\prime} 05^{\prime \prime}$ & $98^{\circ} 35^{\prime} 21^{\prime \prime}$ \\
WO-AZ & Wichita Mts & $34^{\circ} 52^{\prime} 53^{\prime \prime}$ & $110^{\circ} 37^{\prime} 15^{\prime \prime}$ \\
\hline
\end{tabular}

TABLE 2

LIST OF EARTHQUAKES USED

\begin{tabular}{|c|c|c|c|c|c|c|c|}
\hline $\begin{array}{c}\text { Event } \\
\text { No. }\end{array}$ & Date & Time & Lat. (deg) & Long. (deg) & $\begin{array}{l}\text { Depth } \\
(\mathbf{k m})\end{array}$ & Magn. & Region \\
\hline $1^{*}$ & 1963 Sept 25 & $07^{\mathrm{h}} 03^{\mathrm{m}} 54.8^{\mathrm{s}}$ & $16.6 \mathrm{~S}$ & $28.6 \mathrm{E}$ & 33 & 6.0 & Northern Rhodesia \\
\hline $2^{*}$ & 1963 Oct 24 & $07^{\mathrm{h}} 26^{\mathrm{m}} 25.8^{\mathrm{s}}$ & $5.0 \mathrm{~S}$ & $102.8 \mathrm{E}$ & 70 & 6.2 & Sumatra \\
\hline $3 *$ & 1964 Feb 24 & $09^{\mathrm{b}} 52^{\mathrm{m}} 18.6^{\mathrm{s}}$ & $7.2 \mathrm{~S}$ & $67.9 \mathrm{E}$ & 33 & 5.2 & Chagos \\
\hline $4^{*}$ & 1964 Feb 25 & $00^{\mathrm{h}} 34^{\mathrm{m}} 31.5^{\mathrm{s}}$ & $44.6 \mathrm{~S}$ & $37.2 \mathrm{E}$ & 33 & & Prince Edward Island \\
\hline 5 & $1964 \mathrm{Apr} 2$ & $01^{\mathrm{h}} 11^{\mathrm{m}} 55.0^{\mathrm{s}}$ & $5.8 \mathrm{~N}$ & $95.6 \mathrm{E}$ & 132 & 6.7 & Sumatra \\
\hline $6^{*}$ & 1964 Apr 3 & $04^{\mathrm{h}} 12^{\mathrm{m}} 39.7^{\mathrm{s}}$ & $3.9 \mathrm{~N}$ & $96.6 \mathrm{E}$ & 52 & 6.1 & Sumatra \\
\hline $7 *$ & 1964 Apr 8 & $08^{\mathrm{h}} 08^{\mathrm{m}} 11.7^{\mathrm{s}}$ & $6.7 \mathrm{~S}$ & $68.9 \mathrm{E}$ & 33 & 6.3 & Chagos \\
\hline $8^{*}$ & 1964 July 13 & $23^{\mathrm{h}} 43^{\mathrm{m}} 46.3^{\mathrm{s}}$ & $48.2 \mathrm{~S}$ & $31.5 \mathrm{E}$ & 33 & & Prince Edward \\
\hline $9^{*}$ & 1964 Aug 18 & $11^{\mathrm{h}} 09^{\mathrm{m}} 43.6^{\mathrm{s}}$ & $0.4 \mathrm{~N}$ & $67.1 \mathrm{E}$ & 33 & 5.1 & Carlsberg Ridge \\
\hline $10^{*}$ & 1964 Aug 18 & $15^{\mathrm{h}} 26^{\mathrm{m}} 11.9^{\mathrm{s}}$ & $5.7 \mathrm{~N}$ & $57.9 \mathrm{E}$ & 33 & 5.4 & Carlsberg Ridge \\
\hline 11 & 1964 Nov 7 & $18^{\mathrm{h}} 37^{\mathrm{m}} 43.7^{\mathrm{s}}$ & $0.4 \mathrm{~N}$ & $100.1 \mathrm{E}$ & 107 & 5.1 & Sumatra \\
\hline 12 & 1964 Nov 21 & $22^{\mathrm{h}} 40^{\mathrm{m}} 12.0^{\mathrm{s}}$ & $4.9 \mathrm{~S}$ & $103.6 \mathrm{E}$ & 33 & 5.4 & Sumatra \\
\hline 13 & 1964 Nov 24 & $10^{\mathrm{h}} 41^{\mathrm{m}} 33.5^{\mathrm{s}}$ & $6.8 \mathrm{~S}$ & $107.4 \mathrm{E}$ & 125 & 6.0 & Java \\
\hline 14 & 1964 Dec 3 & $03^{\mathrm{h}} 50^{\mathrm{m}} 01.2^{\mathrm{s}}$ & $15.0 \mathrm{~S}$ & $66.8 \mathrm{E}$ & 46 & 6.1 & Mid Indian Rise \\
\hline 15 & $1965 \operatorname{Jan} 5$ & $00^{\mathrm{b}} 51^{\mathrm{m}} 33.6^{\mathrm{s}}$ & $7.3 \mathrm{~S}$ & $106.7 \mathrm{E}$ & 89 & 5.3 & Java \\
\hline
\end{tabular}

* Earthquakes relocated by USCGS using more stations than in the preliminary epicenter determination.

the Sumatra earthquake is larger. In both records we note that, in general, the early arrivals have shorter periods than the main $P_{D F}^{\prime}$ arrival but there is little evidence of dispersion. This agrees with the early observations made by Gutenberg.

The third and fourth traces in Figure 5 are events 4 and 3 recorded at TFO from 
TABLE 3

Recording Stations Used

\begin{tabular}{|c|c|c|c|c|c|}
\hline Event No. & Station Name & $\begin{array}{l}\text { Epicentral } \\
\text { Distance } \\
\text { (deg) }\end{array}$ & $\begin{array}{c}\text { Adjusted } \\
\text { Epicentral } \\
\text { Distance (deg) }\end{array}$ & $\begin{array}{l}\text { Azimuth of } \\
\text { Approach } \\
\text { (deg) }\end{array}$ & Comment \\
\hline \multirow[t]{6}{*}{1} & TFO & 140.01 & & 74 & Velocity filtered \\
\hline & BMO & 139.85 & & 56 & \\
\hline & UBO & 136.82 & & 69 & \\
\hline & $\mathrm{KN}-\mathrm{UT}$ & 140.37 & & 69 & LRSM \\
\hline & LC-NM & 136.63 & & 79 & Velocity filtered, LRSM \\
\hline & BX-UT & 137.64 & & 72 & Velocity filtered, LRSM \\
\hline 2 & TFO & 137.04 & & 305 & \\
\hline \multirow[t]{6}{*}{3} & TFO & 153.03 & 152.67 & 2 & Velocity filtered \\
\hline & WMO & 149.92 & 149.77 & 27 & \\
\hline & $\mathrm{KM}-\mathrm{CL}$ & 152.05 & 151.50 & 349 & LRSM \\
\hline & $\mathrm{KN}-\mathrm{UT}$ & 150.31 & 150.20 & 358 & Velocity filtered \\
\hline & BX-UT & 149.67 & 149.37 & 5 & \\
\hline & DR-CO & 149.62 & 149.32 & 8 & Velocity filtered, LRSM \\
\hline \multirow[t]{7}{*}{4} & TFO & 153.71 & 152.87 & 122 & Velocity filtered \\
\hline & BMO & 161.90 & 161.90 & 98 & \\
\hline & UBO & 155.22 & 154.25 & 111 & \\
\hline & LC-NM & 149.41 & 148.62 & 124 & \\
\hline & KN-UT & 156.18 & 155.62 & 118 & Velocity filtered \\
\hline & BX-UT & 154.02 & 153.12 & 116 & Velocity filtered \\
\hline & DR-CO & 152.80 & 151.42 & 116 & Velocity filtered \\
\hline \multirow[t]{7}{*}{5} & TFO & 132.73 & & 322 & Velocity filtered \\
\hline & WMO & 137.53 & & 339 & \\
\hline & WO-AZ & 132.58 & & 322 & LRSM \\
\hline & $\mathrm{LC}-\mathrm{NM}$ & 136.53 & & 327 & Velocity filtered \\
\hline & $\mathrm{SN}-\mathrm{AZ}$ & 132.85 & & 322 & Velocity filtered, LRSM \\
\hline & DR-CO & 131.75 & & 328 & Velocity filtered \\
\hline & JR-AZ & 131.94 & & 322 & LRSM \\
\hline 6 & TFO & 133.82 & & 320 & \\
\hline 7 & TFO & 152.55 & & 0 & \\
\hline 8 & TFO & 149.75 & & 128 & \\
\hline \multirow[t]{4}{*}{9} & TFO & 145.46 & 146.26 & 3 & \\
\hline & $\mathrm{DR}-\mathrm{CO}$ & 142.03 & 142.83 & 8 & \\
\hline & GE-AZ & 145.93 & 146.88 & 4 & \\
\hline & LG-AZ & 145.35 & 146.25 & 2 & LRSM \\
\hline \multirow[t]{4}{*}{10} & TFO & 138.93 & & 17 & \\
\hline & GE-AZ & 139.24 & & 18 & \\
\hline & LC-NM & 139.34 & & 24 & \\
\hline & $\mathrm{LG}-\mathrm{AZ}$ & 138.88 & & 16 & \\
\hline 11 & TFO & 134.67 & & 313 & \\
\hline 12 & TFO & 136.43 & & 304 & \\
\hline 13 & TFO & 135.07 & & 299 & \\
\hline 14 & TFO & 160.72 & & 6 & \\
\hline 15 & TFO & 135.92 & & 299 & \\
\hline
\end{tabular}


epicenters at Prince Edward Island and the Chagos Archipelago. Both of these events are shallow focus earthquakes at an epicentral distance of about $153^{\circ}$ from TFO. The multiplicity of events introduced by the shallow depth of focus is evident in these records. However, for the Prince Edward Island event the well defined pulse shapes, the time intervals of the events, and the information obtained from velocity filtering allow us to identify the main phases and their multiples. The identification of the various phases from the Chagos earthquake is somewhat less
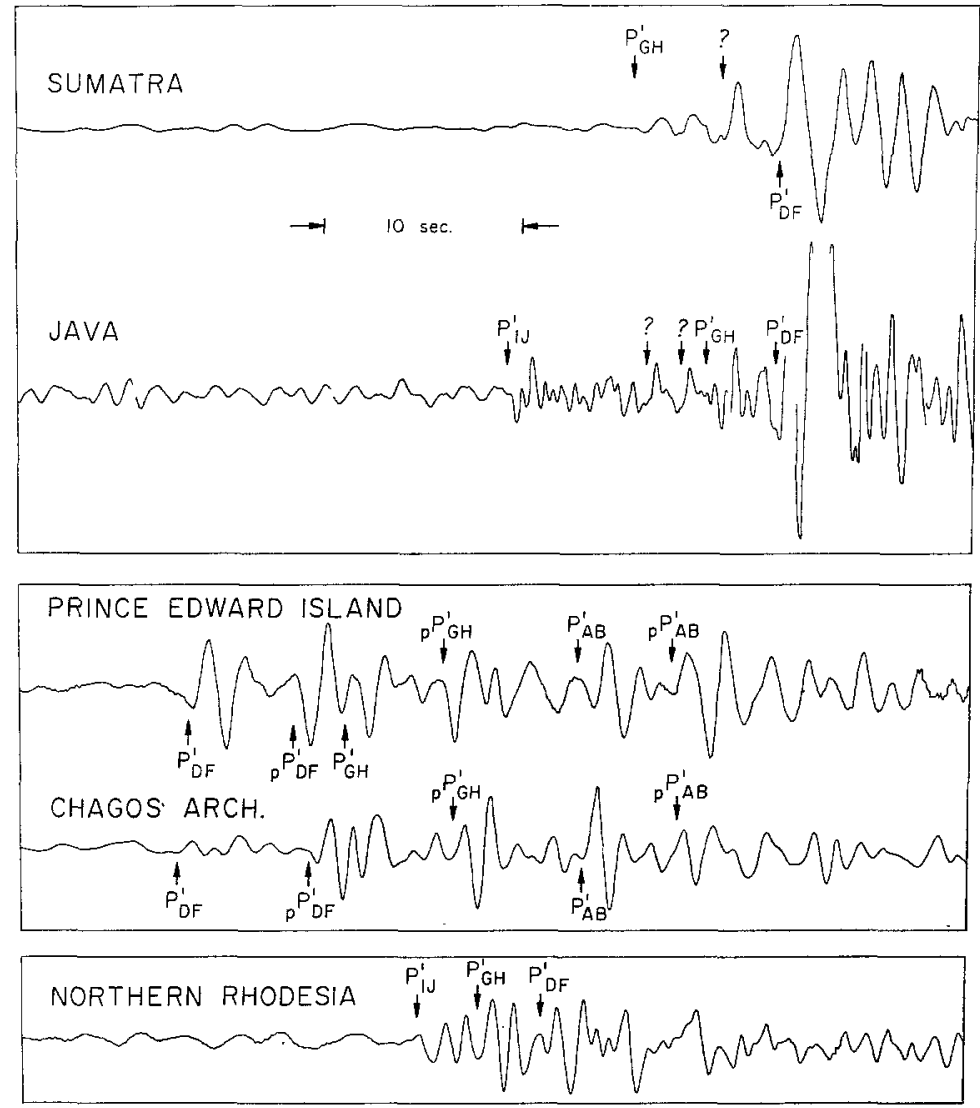

FIG. 5. Examples of core phases recorded at TFO for events no. 5, 13, 4, 3 and 1 in Table 2.

certain when only the same criteria are used. Part of this difficulty may be due to peculiarities in the source radiation pattern which causes the direct arrivals for some phases to be smaller than the reflected arrivals. However, upon including information obtained from the analysis of the Prince Edward Island shock, we can identify the reflections with some certainty and thus infer the presence of the direct arrivals. In both these records, we are not able to identity a distinct phase corresponding to $P_{I . r}^{\prime}$.

The bottom trace in Figure 5 corresponds to event number 1 in Table 2. This is a shallow focus earthquake in Northern Rhodesia recorded at a distance of $140^{\circ}$ from 
TFO. Although many events are well defined on this record, the identification of the phases on the basis of amplitude or relative arrival time alone is difficult at this epicentral distance.

\section{Velocity Filtering}

The raw data for the events listed as "velocity filtered" in Table 3 were obtained in digital form on magnetic tape. The sampling interval was 0.05 sec. After correc-

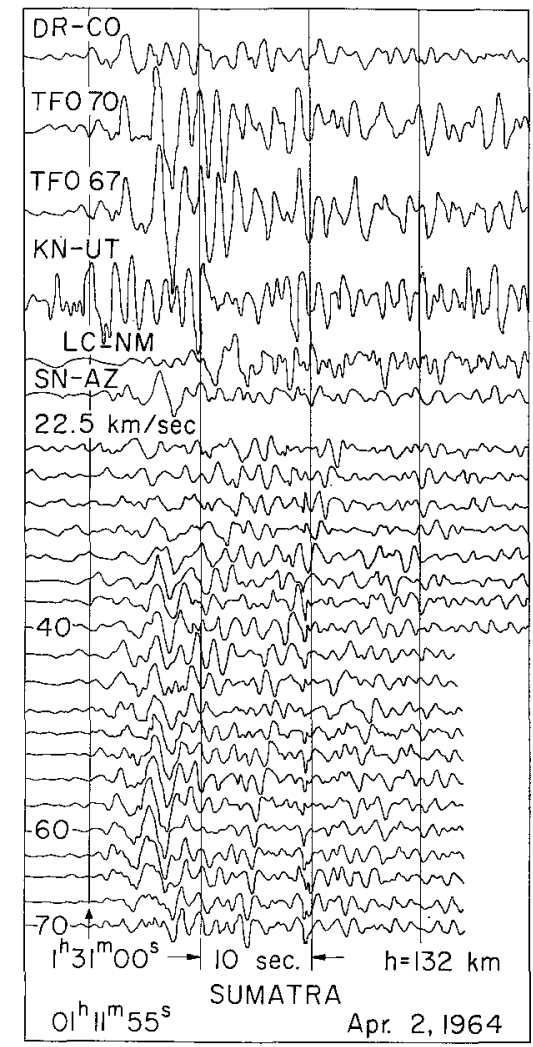

FIG. 6. The original records and the results of velocity filtering for the Sumatra earthquake of 2 April 1964.

tion for the individual instrument magnifications, the digital data were shifted in time and summed on a digital computer.

The time shift was determined by calculating the distances along the direction of approach from the individual stations to a reference point at TFO and then dividing by a selected apparent surface velocity. Summed records for apparent surface velocities ranging from 20 to $100 \mathrm{~km} / \mathrm{sec}$ were obtained in steps of $2.5 \mathrm{~km} / \mathrm{sec}$. Although there were variations in the direction of approach at the individual LRSM stations because of their geographic separation, these variations did not appear to effect the results significantly. The velocity filtered records for the earthquakes located in Sumatra (5-Table 2), Northern Rhodesia (1) and Prince Edward 
Island (4) are shown in Figures 6, 7 and 8. On the upper portion of each figure the records from the individual stations forming the array are shown. The lower portions of the figures show the velocity filtered results with TFO as a reference point.

For the Sumatra event (Figure 6), filtering with an apparent velocity of $55 \mathrm{~km} / \mathrm{sec}$ emphasizes the large event occurring at TFO at $01^{\mathrm{h}} 31^{\mathrm{m}} 05^{\mathrm{s}}$. This velocity is very near that predicted for $P_{D F}^{\prime}$ by all the proposed models. Therefore, using velocity filtering, as well as amplitude and arrival time we can unambiguously identify this event as $P_{D F}^{\prime}$. The smaller event at $01^{\mathrm{h}} 30^{\mathrm{m}} 59^{\mathrm{s}}$ cannot be identified on the basis of

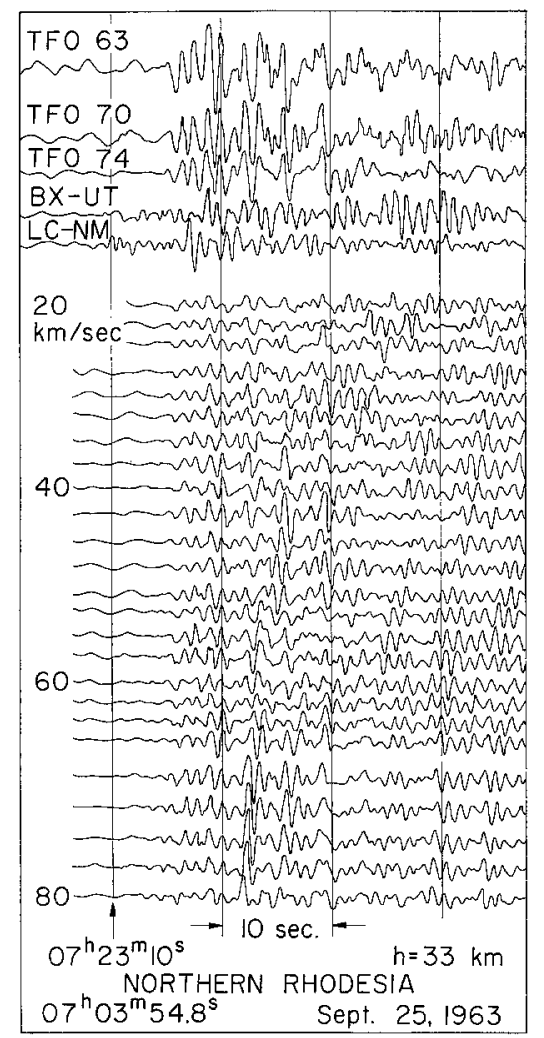

Fig. 7. The original records and the results of velocity filtering for the Northern Rhodesia earthquake of 25 September 1965.

apparent velocity alone, but its arrival time with respect to the established $P_{D_{F}}^{\prime}$ branch can now be precisely determined.

In Figure 7 the results of velocity filtering the records from the earthquake in Northern Rhodesia are shown. TFO is at an epicentral distance such that the travel time curve is complex, and the relative arrival time and amplitudes of the phases are uncertain. The event occurring at $07^{\mathrm{h}} 23^{\mathrm{m}} 22^{\mathrm{s}}$ is maximized for an apparent surface velocity of $70 \mathrm{~km} / \mathrm{sec}$. Since the predicted velocity for $P_{D F}^{\prime}$ at this epicentral distance is between 60 and $70 \mathrm{~km} / \mathrm{sec}$ depending on the model chosen, this event has been identified as $P_{D F}^{\prime}$. This identification is further supported by 
adjusting all of the stations to $P_{D F}^{\prime}$ on the basis of those stations at shorter distances which record $P_{D F}^{\prime}$ unambiguously.

Figure 8 shows a similar display for the Prince Edward Island shock. The problem of phase identification for this earthquake is complicated by the presence of reflections from the free surface and the crust at the source and at the receivers. The epicentral distances at TFO and to DR-CO differ by less than $1^{\circ}$ and yet the relative amplitudes of the first arrivals at the two stations are considerably different. Although we are not certain of the reason for this variation, it is particularly interesting since the TFO records from the Chagos Archipelago shock (Figure 5) are very similar to the DR-CO record for the Prince Edward Island shock.

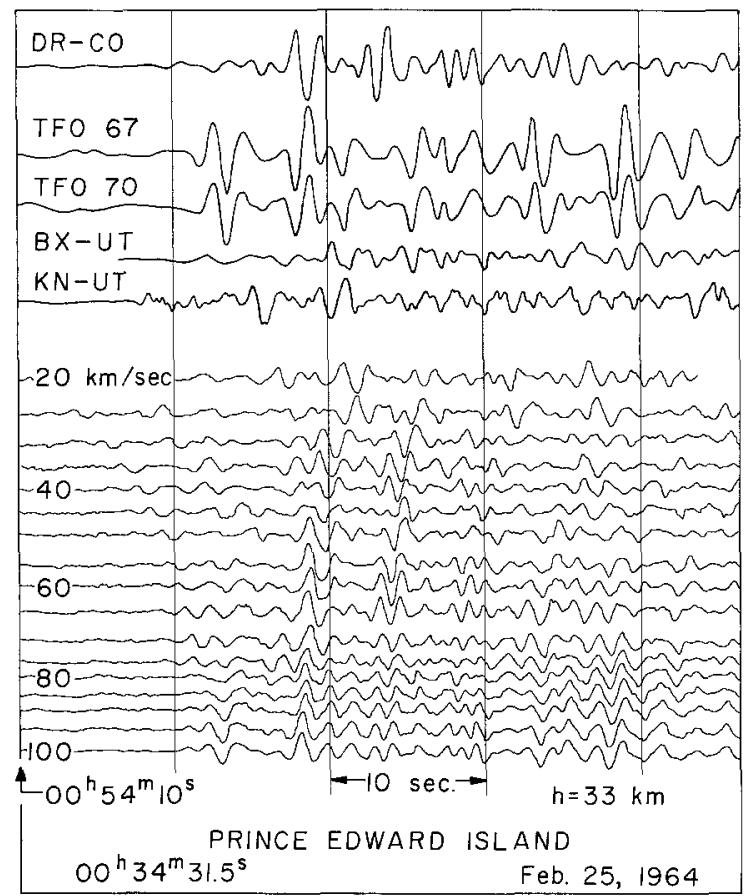

FIG. 8. The original records and the results of velocity filtering for the Prince Edward Island earthquake of 25 February 1964.

The following observations can be made from the velocity filtered records of the Prince Edward shock:

1) The first two phases recorded at TFO are $P_{D F}^{\prime}$ and $p P_{D F}^{\prime}$ with an apparent surface velocity of $90-100 \mathrm{~km} / \mathrm{sec}$.

2) The events occurring at $00^{\mathrm{h}} 54^{\mathrm{m}} 30^{\mathrm{s}}$ and $35^{\mathrm{s}}$ are a direct arrival and its surface reflection. They have apparent surface velocities ranging from 30 to $45 \mathrm{~km} / \mathrm{sec}$. The lack of precision in the measured apparent surface-velocity suggests that both $P_{I J}^{\prime}$ and $P_{G H}^{\prime}$ and their multiples may be present. However, the evidence is far from conclusive because of the small number of stations used for velocity filtering. The apparent surface velocities of this event rule out the possibility that these are multiple events introduced by crustal layering. 
3) The events occurring at $00^{\mathrm{h}} 54^{\mathrm{m}} 42^{\mathrm{s}}$ and $47^{\mathrm{s}}$ appear to be complex events composed of $P_{A B}^{\prime}$ and $p P_{A B}^{\prime}$ maximizing at apparent surface velocities of 20 to $25 \mathrm{~km} / \mathrm{sec}$, and crustal multiples and possibly phases similar to $P_{I J}^{\prime}$ maximizing at higher velocities. Of these possibilities, only the events $P_{A B}^{\prime}$ and $p P_{A B}^{\prime}$ were identified.

\section{Travel Time Curves}

Once the phases were identified on the seismograms which were velocity filtered, the times were corrected to those of surface focus and plotted as conventional travel time curves (Figures 9 and 10). The times from the unfiltered records were also plotted using the velocity filtered records as a guide. At distances less than $140^{\circ}$ the travel times of the phase with largest amplitude were adjusted to agree with the

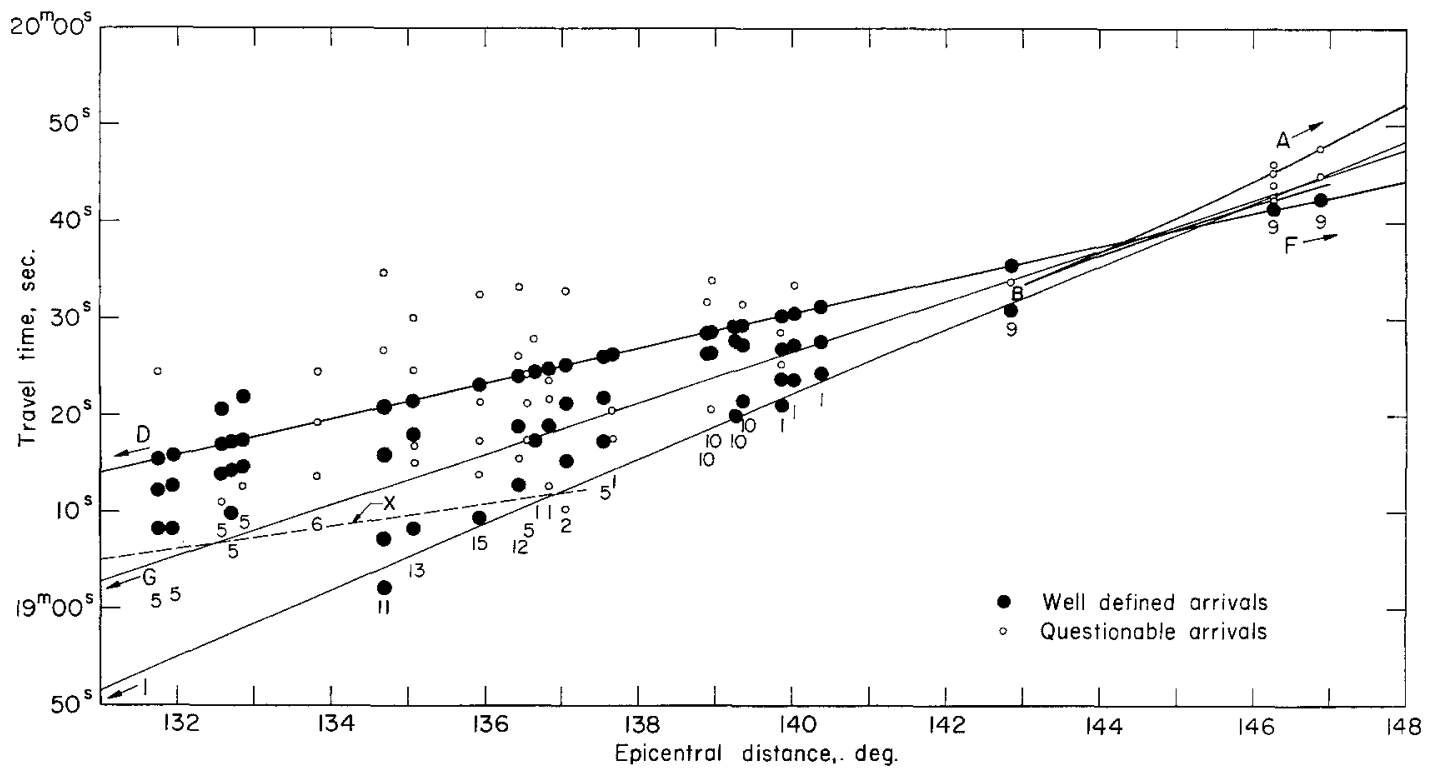

FIG. 9. Observed travel times (adjusted to the standard Jeffreys' curves) for $P K P$ phases in the range $131^{\circ}$ to $148^{\circ}$. The heavy solid line is the Jeffreys curve, the light solid lines are the precursors predicted by Adams and Randall, and the dashed line is the $X$ branch of Hai.

Jeffreys' curve for $P_{D F}^{\prime}$. At distances greater than $148^{\circ}$, the travel times and epicentral distances of the events were adjusted to allow the phases identified as $P_{D F}^{\prime}$ and $P_{A B}^{\prime}$ to agree with Jeffreys' travel time curves. The time shifts were only several seconds and the adjusted changes in epicentral distance were less than one degree. For those earthquakes recorded at many LRSM stations, these revisions were found to be consistent.

In Figure 9, there is a strong indication of two precursors to $P_{D F}^{\prime}$ in the epicentral range from $135^{\circ}$ to $140^{\circ}$, but there is a noticeable gap of observational data at the critical distance of $132^{\circ}$. In the $135^{\circ}$ to $140^{\circ}$ range our observations would tend to support those of Adams and Randall although it is clear that more data, perhaps statistically tested, are required to discriminate between the proposed models of Bolt and Adams and Randall. 
The data from $146^{\circ}$ to $163^{\circ}$ (Figure 10) support previous observations of Gutenberg, Bolt, Adams and Randall, and Hai regarding the presence of an intermediate branch $P_{G H}^{\prime}$. In the range from $154^{\circ}-156^{\circ}$ there are two arrivals near $20^{\mathrm{m}} 10^{\mathrm{s}}$ which we could not identify with certainty as either another phase or a crustal multiple. A similar observation may be made concerning the intermediate phases near $161^{\circ}$. These observations may indicate the presence of an additional branch to $P_{G H}^{\prime}$

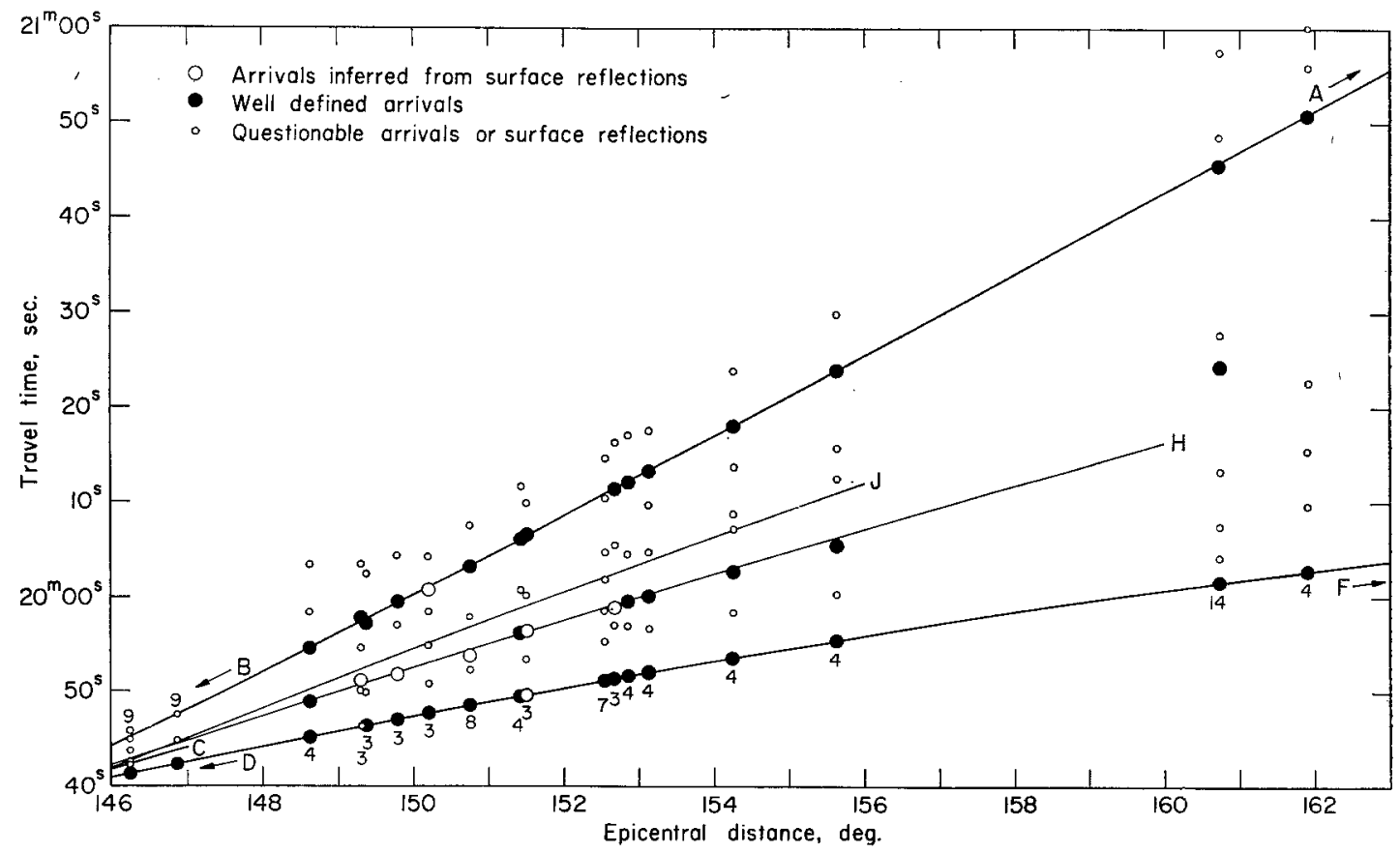

FIG. 10. Observed travel times (adjusted to Jeffreys' curves) for PKP phases in the distance range $146^{\circ}$ to $163^{\circ}$. The heavy solid lines are the Jeffreys curves; the light solid lines are the branches predicted by Adams and Randall. The cusp at $C$ is placed at the distance given by Jeffreys and Bullen.

\section{Conclusions}

Core phases, arising from the transition zone at the boundary of the inner core, were studied on seismograms recorded at the Tonto Forest array and many of the surrounding LRSM stations. Velocity filtering, in the form of time delaying and summation across the large array, was used to supplement conventional amplitude and travel time methods in the study of these core arrivals. Utilization of the apparent surface velocity is a useful technique when applied to the analysis of seismic core phases.

From this study we have concluded that there is a strong indication of two short period precursors to the main $P_{D F}^{\prime}$ arrival at distances less than $140^{\circ}$ and the amplitudes of these phases are less than $P_{D F}^{\prime}$. At least one of these precursors is an intermediate arrival to $P_{D F}^{\prime}$ and $P_{A B}^{\prime}$ at distances greater than $145^{\circ}$. The observed 
apparent velocity of this arrival suggests that it is an extension of the $P_{G B}^{\prime}$ precursor observed at distances less than $140^{\circ}$. The amplitude of $P_{G H}^{\prime}$ is often equal to or greater than $P_{A B}^{\prime}$ and $P_{D F}^{\prime}$ at distances greater than $143^{\circ}$.

The phase $P_{I J}^{\prime}$ is small at distanices less than $140^{\circ}$ but in some earthquakes examined, this phase was absent. Beyond $145^{\circ}$ there are some indications that $P_{I J}^{\prime}$ exists but the identifications of the arrivals are uncertain.

Our data appear to support most nearly the velocity solution for the core proposed by Adams and Randall (1964), although it is clear that more data in the epicentral distance range of $130^{\circ}$ to $134^{\circ}$ are required to discriminate between competing models. This study has indicated, however, that velocity filtering of core phases does provide valuable supplementary information. Even though absolute epicentral locations may not be known, the observed apparent velocities can be used for phase recognition and discrimination against unwanted signals. Future analyses, however, must correct for the effects of local crustal structure beneath the array.

\section{ACKNOWLEDGMENTS}

The authors wish to thank Dr. S. T. Algermissen and the U. S. Coast and Geodetic Survey for their assistance in relocating some of the epicenters, and United Electrodynamies for supplying the digital tapes.

This research was supported by the Advanced Research Projects Agency and was monitored by the Air Force Office of Scientific Research under Contract AF-49(638)-1337.

\section{REFERENCES}

Adams, R. D., and M. J. Randall (1963). Observed triplification of PKP, Nature 200, 744-745. Adams, R. D., and M. J. Randall (1964). The fine structure of the earth's core, Bull. Seism. Soc. Am. 54, 1299-1313.

Bolt, B. A. (1962). Gutenberg's early PKP observations, Nature, 196, 122.

Bolt, B. A. (1964). The velocity of seismic waves near the earth's center, Bull. Seism. Soc. Am. $54,191-208$.

Gutenberg, B. (1957). The boundary of the earth's inner core, Am. Geophys. Union Trans. $38,750-753$.

Gutenberg, B. (1958a). Causties produced by waves through the earth's core, Geophys. J. 3, $238-248$.

Gutenberg, B. (1958b). Wave velocities in the earth's core, Bull. Seism. Soc. Am. 48, 301-314.

Gutenberg, B. (1959). Physics of the Earth's Interior. Academic Press, 111-113.

Gutenberg, B., and C. F. Richter (1938). $P^{\prime}$ and the earth's core, Mon. Not. R. A. S., Geophys. Suppl. 4, 363-372.

Hai, N. (1961). Propagation des ondes longitudinales dans le noyeau terrestre d'apres les seismes profonds de lles Fidji, Ann. Geophys. 17, 60-66.

Hai, N. (1963). Propagation des ondes longitudinales dans le noyeau terrestre, Ann. Geophys. $19,285-346$.

Jeffreys, H. (1939a). The times of the core waves, Mon. Not.R. A. S., Geophys. Suppl.4, 548-561.

Jeffreys, H. (1939b). The times of the core waves, Mon. Not. R. A. S., Geophys. Suppl.4, 594-615.

Lehmann, I. (1936). $P^{\prime}$, Publs. Bur. Central Seism. Intern. Trav. Sci., (A), 14, 87-115.

Seismological Laboratory

California Institute of Technology

Pasadena, California

Division of Geological Sctences

Contribution No. 1357

Manuscript received August 2, 1965. 